\title{
Theoretical Aspects of Spinal Osteochondrosis Patient Psychological Characteristic Study
}

\section{Aspectos teóricos del estudio de las características psicológicas de los pacientes con osteocondrosis espinal}

\author{
Nurakhmetov Timur Med'khatovich* \\ Moscow University for the Humanities, 5, Russia \\ ORCID: https://orcid.org/0000-0003-0306-6905
}

*Correspondence

Email: t.nurakhmetov@bk.ru
Cite as:

Nurakhmetov, T. (2020). Theoretical aspects of spinal osteochondrosis patient psychological characteristic study. Propósitos y Representaciones, 8(2), e475. Doi: http://dx.doi.org/10.20511/pyr2020.v8n2.555 


\section{Summary}

Spinal osteochondrosis is an urgent problem of modern medicine, sociology, psychology, and a number of other disciplines. The interdisciplinary status of degenerative-dystrophic diseases of the spine is indicated by the fact that they are a manifestation of both a number of somatic and neurological diseases. Every year the number of patients with this pathology rapidly grows. According to studies, they affect up to $90-97 \%$ of the adult population and represent an economic burden, since rehabilitation treatment of patients involves significant financial costs. The article provides a theoretical analysis of existing studies related to the study of the influence of individual psychological characteristics of patients with spinal osteochondrosis.

Keywords: Individual Psychological; Characteristics of Patients; Spinal Osteochondrosis.

\section{Resumen}

La osteocondrosis espinal es un problema actual de la medicina moderna, la sociología, la psicología, y de otras disciplinas. El estado interdisciplinario de las enfermedades degenerativodistróficas de la columna vertebral indica, que son una manifestación como una serie de enfermedades somáticas y neurológicas. Cada año el número de los pacientes con esta patología aumenta rápidamente. Según los datos de las investigaciones, del 90-97\% de la población adulta representan un problema económico, pues el tratamiento rehabilitación de los pacientes implica un costo financiero considerable. El artículo cita un análisis teórico de estudios existentes, relacionados con el estudio de la influencia de las características psicológicas individuales de pacientes con osteocondrosis espinal.

Palabras clave: Características psicológicas individuales; Pacientes; Osteocondrosis espinal

\section{Introduction}

According to medical statistics, degenerative-dystrophic diseases of the spine in the structure of disability account for 20.4\% (Abramov \& Abramova 1996). Disability occurs with a relatively short duration of the disease, and, as a rule, in people of working age. In most cases, back pain is relatively benign, pain syndromes disappear within $1-2$ weeks, and $66-75 \%$ of patients, after stopping an acute pain episode, feel minor pain for another month.

The disease pathogenesis is based on the process of the intervertebral disc degeneration with subsequent changes in the adjacent vertebrae, intervertebral joints and ligamentous apparatus (Pineginm, Rublevskaia \& Khaitov 2000). Pathology of the peripheral nervous system associated with spine osteochondrosis is a common cause of performance loss. Every year a number of young people suffering from vertebral neurological diseases increases. Very often they become the cause of disability at an early age. The clinical manifestations of spinal osteochondrosis disease are represented by compression-ischemic and reflex muscular-tonic syndrome groups. In the first case, the spinal root is pinched, accompanied by acute pain, in the second - a spasm of the paravertebral muscle occurs without involving the root itself. The first dystrophic changes in the intervertebral disc are observed at the age of 20 years. Particular progression is observed after 40 years. However, there are still no comprehensive studies of the individual psychological characteristics of patients with osteochondrosis, and there is no clear adaptation system for such patients in society.

The most frequently affected mobile parts of the spinal column are the cervical, lumbar, and less commonly the thoracic section (Popelianskii, 1992). 


\section{Problem statement}

Spinal osteochondrosis limits the life of patients, reduces the quality of life, changes the psyche and behavior of people (50\% of patients have signs of chronic emotional stress (Popelianskii 1992; Walter, Vaitl \& Frank 1998).

At the same time, debatable questions are about the influence of the personality's mental qualities on the development of spinal osteochondrosis, and whether psychological qualities predetermine the development of osteochondrosis or they are a manifestation of the underlying disease (see works by Chubar, 1983; Tretiakova, 1988; Vein, Voznesenskaia \& Golubev, 1998; Averkina \& Filatova, 2000).

\section{Discussion}

The analysis of the scientific literature shows that to date rehabilitation medicine has few combination, clinically justified measures that are aimed at the rehabilitation of patients with spinal osteochondrosis. Grigorieva and Gustov (1997) based on the medical and statistical characteristics of patients with neurological manifestations of spinal osteochondrosis developed a scientifically-based system of measures aimed at rehabilitation treatment of this group of patients. Scientists studied the primary incidence, as well as the prevalence of vertebroneurological pathology among the adult population of large industrial centers, the level and structure of hospitalized morbidity, and the biomedical and socio-hygienic factors that contribute to the onset of vertebro-neurological pathology among urban residents of working age.

Stebunov in his thesis research "System of medical and psychological rehabilitation of patients with spinal osteochondrosis in a medical rehabilitation center" (2010) presented the results of studies conducted in 2005-2007 in LLC 'Workshop of Health Rehabilitation Center', Vyborgsky district, St. Petersburg.

In this work, as key factors determining the personality of a sick person with spinal osteochondrosis, we consider 1) the quality of life; 2) the characteristic features of patients with spinal osteochondrosis, the attitude towards the disease, as well as the changes that occur with the patient.

\section{Quality of life of a patient with spinal osteochondrosis}

Practical studies of the quality of life of patients with spinal osteochondrosis are not carried out in our country. Nevertheless, when characterizing the quality of life of patients with degenerativedystrophic diseases of the spine, it is necessary to consider the following aspects of quality of life: health, social status, activity, marital status, and mental state. We shall consider each of these aspects.

Health. According to the WHO, neurological symptoms of spinal osteochondrosis are observed in $40-80 \%$ of the adult population of the planet. In $70 \%$ of cases, chronic forms of the disease lead to temporary disability, up to $10 \%$ of patients become disabled (Belova 2002). In $27 \%$ of cases, temporary disability is observed. In $3 \%$ - complete disability.

Osteochondrosis manifests itself first in a direct damage to the vertebral structures themselves: cervicalgia (cervical spine), dorsalgia (thoracic spine) and lumbalgia (lumbar spine), as well as a large group of extravertebral syndromes - neurodystrophic, neurovascular and muscular-tonic (Khabirov, 2002)

Social status. Total or partial disability leads to a change in material well-being, as a rule, to deterioration. However, in the case when labor activity did not seem to be particularly significant for a patient with spinal osteochondrosis, an attitude to return to work did not arise. 
And the possibility of obtaining certain social benefits, for example, disability pension, strengthens the conditional desirability of the disease (Grigorieva \& Gustav 1997).

Activity. The nature of the disease of spinal osteochondrosis is such that it affects the activity of patients. The following syndromes are identified that reduce activity:

1) Pain: a) cervicalgia - intense dull pain in the deep parts of the neck. It is most pronounced in the morning, after sleep, aggravated by turning the head, coughing, sneezing, laughing; b) cervicocranialgia - pain localized in the neck, occipital region, head; c) cervicocranialgia - pain in the neck, occipital region, head; c) cervicobrachialgia - pain in the neck, which is combined with aching pain in the deep parts of the shoulder and forearms (autonomic, sclerotomic pain).

2) muscle-tonic, which arise indirectly due to the constant irritation of nociceptive (pain) receptors around the degenerated disk and joints with excitation of the segmental apparatus of the spinal cord, including motor neurons (especially g-mononeurons).

Marital status. A significant role in the life of a patient with spinal osteochondrosis is his social environment and, first of all, his family. Family support is an important supporting psychological factor. In the case it lacks for some reason, the family is a source of stress.

Mental state. The debatable and still unresolved issue is the psychosomatics of spinal osteochondrosis. Kleimenov (1989) solves the question of the ratio of mental and organic in the lumbar spine conditions as follows: identifies four variants of the course of the disease. In the first, there are no signs of organic damage to both the spine and the peripheral nervous system but neurotic disorders are observed. In the second, signs of vertebral damage to the peripheral nervous system are observed. In the third, there are neurological manifestations of lumbar osteochondrosis and neurotic disorders that develop after the formation of a pain syndrome are combined. In the fourth, neurotic and affective disorders are absent.

The causes of psychological problems in patients with spinal osteochondrosis include the emotional impact of the diagnosis, high psychosomatic correlation, duration of treatment, disease progression, accompanied by physical symptoms of pain and weakness.

\section{Characteristic features of the personality of patients with spinal osteochondrosis}

Foreign researchers noted in their works that patients with non-inflammatory diseases of the musculoskeletal system often have psychogenic diseases or psychological trauma in childhood, marriage, etc. Maxwell, Gatchel \& Mayer (1998) made it possible to conclude that patients with chronic pain in the neck and lower back have a psychogenic component: shyness, indecision, emotionality. Patients with spinal osteochondrosis have constitutional personality characteristics in the form of increased aggressiveness and at the same time inhibition and passivity, feelings of pride and desire for independence.

Domestic researchers note that about $60 \%$ of patients with spinal osteochondrosis reported the role of a traumatic situation in the occurrence of pain.

\section{The influence of the psycho-emotional sphere of personality on the pathogenesis of spinal osteochondrosis}

Following Grigorieva (1997), we believe that the development of psycho-emotional stress is influenced by the individual and personal characteristics of patients.

As a result of exposure to stressful factors, skeletal muscle tension develops, and, as a result, the "block" of the vertebral segment. The psychological characteristics of the personality associated with psychological stress and, as a result, expressed anxiety, contribute to excessive 
activation of the sympathoadrenal system, a decrease in peripheral blood circulation, and a number of other changes that ultimately lead to local ischemia and the formation of pain. In addition to the above, chronic stress leads to a change in the motor stereotype, which enhances the pain resulting from the tension of muscle groups (Vein, Voznesenskaia \& Golubev 1998; Mendelevich 1998). The peripheral pain focus leads to anxiety, impaired attention.

Most scientists (Ampilova 1986, Varapanov \& Iuriev, 1994; Walter, Vaitl \& Frank 1998; Hadjistavropoulos \& La Chapelle 2000) associate the stateof anxiety and depression with the duration of the course of the disease and the response to pain. Klapow, Slater and Patterson (1995); Chew and May (1997) note the correlation of neurological manifestations of patients with the severity of the disease and increasing mental maladaptation.

Klapow, Slater and Patterson (1995) believes that emotional stress in patients with lumbar spinal osteochondrosis can be either a consequence of a violation of the relationship between the individual and the environment, or a consequence of the characteristics of an individual reaction to the disease. A major role in the perception of the disease is played by the psycho-emotional state of the individual with spinal osteochondrosis. Perrot (2000), Procor, Gatchel and Robinson, 2018) argue that a person's response to a disease or pain is often greater than the severity of the disease.

Intrapersonal conflicts (Baburina 2006), mental rigidity, and psychogenic disorder in itself, play a major role in the course of a disease of the musculoskeletal system, being due to the severity of the course of osteochondrosis and serving as a link in the psychosomatic variant of pathogenesis.

Proponents of the autoimmune concept of spinal osteochondrosis (Pinegin, Rublevskaia $\&$ Khaitov 2000) believe that stress provokes the occurrence of autoimmune reactions. A severe psycho-emotional state of a person leads to a violation of the nervous regulation of the immune system. The involvement of the limbic-diencephalic system reduces the number of $\mathrm{T}$ lymphocytes, which is a source of the formation of an autoimmune reaction.

However, not all scientists agree with the relationship of the influence of the psychoemotional sphere of the personality on the pathogenesis of spinal osteochondrosis. Grigorieva and Gustov (1997) believe that psychosomatics is not decisive in the development of spinal osteochondrosis.

Romanenko (1996) believes that the peripheral pain center, depending on the lateralization of the process and gender, blocks the reaction of the contralateral hemisphere to a modally-specific load, leading to the occurrence of psychophysiological personality disorders. In patients with left-sided vertebrogenic syndrome, a pattern of psychophysiological disorders similar to neurotic disorders occurs.

\section{Conclusiones}

The rapid increase in the number of patients with spinal osteochondrosis indicates the somatoneurological status of the disease. Restorative medicine tends to recognize the key role of the individual personality characteristics of patients in the development of degenerative-dystrophic spinal diseases. The available rehabilitation programs in comprehensive rehabilitation medicine, of course, take into account the mental properties of the person, however, vertebro-neurological pathology requires a new individual-personality approach to patients.

The development and course of spinal osteochondrosis is influenced by the quality of life of patients, psychological qualities and changes that occur with the patient. Indicators of the quality of life of patients with spinal osteochondrosis are health, social status, activity, marital status, and psychological state. 
Spinal osteochondrosis is observed in a significant part of the adult population. It has gender- and age-related features. To a greater extent, men are affected, to a lesser extent, women. There is an age-related dynamic of the incidence: with age, spinal osteochondrosis covers an increasing number of people.

In $10 \%$ of cases, spinal osteochondrosis leads to disability, which entails a change in the social role and status of the patient. In some cases, obtaining social benefits, including disability pension leads to the perception of the disease as a desired event.

Spinal osteochondrosis leaves an imprint on the activity of patients. Pain and muscletonic symptoms lead to a decrease in activity. The nature of the disease and the duration of its course lead to neurotic disorders. Characteristic personality traits with osteochondrosis of the spine are:

- anxiety-neurasthenic and ergopathic type of response to the disease;

- mental trauma in the past and present;

- psychogenic component in the structure of personality.

A significant influence on the pathogenesis of spinal osteochondrosis is exerted by the psycho-emotional sphere of the patient's personality:

- anger, excitement, fear, and stress, which lead to a change in motor stereotype;

- anxiety and depression associated with the duration of the disease and the response to pain;

- increasing mental maladjustment;

- intrapersonal conflicts, mental rigidity.

\section{References}

Abramov, V.V., \& Abramova T.Ia. (1996). Asymmetry of the nervous, endocrine, and immune systems. Russia, Novosibirsk, p. 99.

Ampilova, N.V. (1986). The state of higher nervous activity in patients with neurological manifestations of lumbar osteochondrosis, Proceedings of the III Congress of neuropathologists and psychiatrists of Belarus, Minsk, pp. 49-50.

Averkina, N.A., \& Filatova, E.G. (2000). Psychological factors in chronic pain. S.S. Korsakov Journal of Neurology and Psychiatry, 100(12), 21-27.

Baburin, I.N. (2006). Clinical and psychological characteristics of patients with chronic pain syndrome due to lumbosacral osteochondrosis: author's abstract, Candidate of Medicine, Russia, 151.

Belova, A.N. (2002). Scales, tests, and questionnaires in medical rehabilitation, Moscow, Russia, 397

Chew, C.A., \& May, C.R. (1997). The benefits of back pain, Family Practice, 14(6), 461-465.

Chubar, V.A. (1983). The role of emotional factors in the occurrence of pain of lumbar syndromes: author's abstract, Candidate of Medicine, p. 24.

Grigorieva, V.N., \& Gustov, A.B. (1997). A new approach to psychotherapy of patients with chronic pain syndrome with spinal osteochondrosis, Organization of medical care for patients with pain syndromes: theses of the Russian scientific-practical conference, Russia, Novosibirsk, pp. 121-135.

Grigorieva, V.N., \& Gustov, A.B. (1997). Psychological characteristics of patients with neurological manifestations of lumbar osteochondrosis. S.S. Korsakov Journal of Neurology and Psychiatry, 3, 12-15.

Hadjistavropoulos, H.D., \& La Chapelle, D.L. (2000). Extent and nature of anxiety experienced during physical examination of chronic low back pain. Behavior research and Therapy, 38(1), 13-29. doi: http://dx.doi.org/10.1016/s0005-7967(99)00024-8

Khabirov F.A. (2002). Clinical neurology of the spine, Russia, Kazan, p. 472. 
Klapow, J.C., \& Slater, M.A., \& Patterson, T.L. (1995) Psychosocial factors discriminate multidimensional clinical groups of chronic low back pain patients. Pain, 62(11), 349355.

Kleimenov, V.N. (1989). Clinical options for psychosomatic and somatopsychic relationships in patients with neurological manifestations of lumbar osteochondrosis: author's abstract, Candidate of Medicine, Russia, Novosibirsk, p. 18.

Maxwell, T.D., \& Gatchel, R.J., \& Mayer, T.G. (1998). Cognitive predictors of depression in chronic low back pain: toward an inclusive model. Journal of Behavorial Medicine, 21(2), 131-143. doi: http://dx.doi.org/10.1023/a:1018723823523

Mendelevich, V.D. (1988). Psychological evaluation of nosological independence of neurosis, Kazan Medical Journal, 1, 56-59.

Perrot S. (2000) Factors in the chronic progression of common low back pain. La Revue du Patricien, 50(6), 1170-1173.

Pinegin B.V., \& Rublevskaia I.V., \& Khaitov P.M. (2000). Autoimmune concept of spinal osteochondrosis and the feasibility of using immunocorrective drugs. Bulletin of new medical technologies, 7(1), 92-94.

Popelianskii, Ia.Iu. (1992). Neurosis and osteochondrosis are the most common multifactorial human diseases. Vertebroneurology, 2, 22-26.

Proctor, T., \& Gatchel, R.J., \& Robinson R.C. (2018). Psychosocial factors and risk of pain and disability, Occupational Medicine, 15(4), 803-812.

Romanenko, I.V. (1996) Central and peripheral mechanisms of pain myofascial syndromes: Author's abstract, Ph.D. Medicine, p. 24.

Stebunov B.A. (2010) The system of medical and psychological rehabilitation of patients with spinal osteochondrosis in a medical rehabilitation center, Russia, p. 189.

Tretiakov, V.P. (1988) To the assessment of functional complaints of patients with dystrophic spinal damages, Prevention and treatment of neurological diseases, Russia, Kazan, pp. 120-123.

Varapanov V.A., \& Iuriev P.V. (1994) Some psychological and functional criteria for evaluating the effectiveness of complex treatment of patients with depressive syndrome with spinal osteochondrosis, Problems of balneology, physiotherapy, and therapeutic exercises, 5, 23-25.

Vein A.M., \& Voznesenskaia T.G., \& Golubev V.L. (1998) Depression in neurological practice, Russia, p. 128.

Walter B., \& Vaitl D., \& Frank R. (1998) Affective distress in fibromyalgia syndrome is associated with pain severity. Rheumatol, 57(2), 101-104. 